\title{
Artificial Neural Network- (ANN-) Based Proxy Model for Fast Performances' Forecast and Inverse Schedule Design of Steam-Flooding Reservoirs
}

\author{
Yuhui Zhou $\mathbb{D}^{1,2}$ Yunfeng Xu, ${ }^{1,3}$ Xiang Rao ${ }^{1},{ }^{1,3}$ Yujie Hu, ${ }^{3}$ Deng Liu, ${ }^{3}$ and Hui Zhao ${ }^{3}$ \\ ${ }^{1}$ Cooperative Innovation Center of Unconventional Oil and Gas (Ministry of Education \& Hubei Province), Yangtze University, \\ Jingzhou, China \\ ${ }^{2}$ National Coal Chemical Product Quality Supervision and Inspection Center, Huainan 232001, Anhui, China \\ ${ }^{3}$ School of Petroleum Engineering, Yangtze University, Wuhan 430100, China
}

Correspondence should be addressed to Xiang Rao; raoxiang0103@163.com

Received 14 January 2021; Accepted 28 April 2021; Published 8 May 2021

Academic Editor: José Francisco Gómez Aguilar

Copyright (C) 2021 Yuhui Zhou et al. This is an open access article distributed under the Creative Commons Attribution License, which permits unrestricted use, distribution, and reproduction in any medium, provided the original work is properly cited.

\begin{abstract}
Steam flooding is one of the most effective and mature technology in heavy oil development. In this paper, a numerical simulation technology of steam flooding reservoir based on the finite volume method is firstly established. Combined with the phase change of steam phase, the fully implicit solution for steam flooding is carried out by using adaptive-time-step Newton iteration method. The Kriging method is used for stochastically to generate 4250 geological model samples by considering reservoir heterogeneity, and corresponding production schedule parameters are randomly given; then, these reservoir model samples are handled by the numerical simulation technology to obtain corresponding dynamic production data, which constitute the data for artificial neural network (ANN) training. By using the highly nonlinear global effect of artificial neural network and its powerful self-adaptive and self-learning functions, the forward-looking and inverse design ANN models of steam-flooding reservoirs are established, which provides a new method for rapid prediction of steam-flooding production performance and production schedule parameter design. In 4250 samples, the error of the forward-looking model is basically less than $0.1 \%$, and the error of the inverse design model is generally less than 15\%. It fully shows that the ANN models developed in this paper can quickly and effectively predict oil production and design production parameters and have an important guiding role in the implementation of the steam flooding technology. Finally, the forward-looking ANN model is applied to efficiently analyze the influencing factors of steam flooding process, and uncertainty analysis of the inverse design ANN model is conducted by Monte Carlo Simulation to illustrate its robustness. Besides, this paper may provide a reference for the application of neural network models to underground oil and gas reservoir, which is a typical invisible black box.
\end{abstract}

\section{Introduction}

At present, heavy oil resources are rich in the world. Heavy oil, extra heavy oil, asphalt, and oil sands account for about $70 \%$ of the global oil resources. Their huge resources also determine the important role and position in the future energy strategy. For heavy oil development, steam flooding is one of the most effective and mature methods. However, the cost of steam flooding is high. In today's low oil price, it is very important to accurately grasp the production performance and steam front edge of steam drive and successfully realize the effective development of steam drive oilfield [1-6].

Wei et al. [7] have carried out detailed laboratory experiments on the mechanism of steam flooding and believe that the main mechanisms of steam flooding are steam distillation, temperature rise and viscosity reduction, and in situ dissolution. Based on the laboratory experiment of steam flooding, Ma et al. [8] obtained an optimal steam injection rate and the relationship between injection rate and crude oil production. Johnson et al. [9] tried the steam distillation experiment of crude oil in the laboratory and 
successfully separated the distillation effect of steam from the process of steam flooding. Shen [10] carried out laboratory steam flooding experiments using the physical model, and the experimental results showed that steam quality was positively correlated with oil recovery. At present, the research on displacement mechanism and technology of steam flooding has been relatively perfect, but the research on the mathematical model is still not mature. Marx and Langenheim [11] put forward the piston-type steam flooding reservoir model, which laid the theoretical foundation of steam injection of thermal oil recovery. Van Lookeren [12] proposed a prediction model of steam front for radial steam flow. Considering gravity override, the conception of shape factor was used to characterize the gravity override degree of steam and optimize the steam injection rate. Chen [13] established an analytical model for steam-flooding performance prediction on the basis of previous studies and divided the reservoir into original oil area, oil enrichment area, hot water area, and steam area. Torabzadeh and Kumar [14] model is used to normalize the historical performance data (steam injection heat and oil production) of the same or similar oilfield, and polynomial is used to fit the relationship curve between normalized oil production and steam injection. The regression coefficients of each scheme are correlated with reservoir parameters to predict the steam drive performance of the same or similar oilfield. The prediction accuracy is limited by the historical data onto the oilfield, and it is only applicable to the reservoirs with similar properties. After that, many scholars put forward a variety of theoretical models of steam flooding performance prediction on the basis of previous studies. Although each method has its own advantages, each has its own limitations.

In recent years, artificial neural network (ANN) as a nonlinear mapping model has been widely used in reservoir injection production performance prediction. For the typical edge and bottom water reservoirs in offshore nonwaterflooding development with simple structural background and relatively complete layered test data, Gao et al. [15] applied neural network technology to predict the remaining oil saturation distribution in different periods. BP algorithm was used to effectively predict the rock compressibility of reservoirs in two areas of Jilin Oilfield [16], taking pressure and porosity as input layer parameters and rock compressibility as output layer parameters. The correlation analysis was carried out according to many relations affecting oil production, and the prediction model of oil production was established by using ANN [17]. Sun and Ertekin [18] built a decision-making tool for cycle steam simulation based on ANN, which was used to study the cyclic steam huff and puff process. Rao et al. [19] used the embedded discrete model to generate a large number of sample data and trained a forward and inversion model based on ANN, which was used to predict oil-water production in water huff and puff development. The above studies show that ANN is a powerful tool to solve the forward and inversion problems in oilfield development [19-24], but there is no ANN-based model to study the production performance prediction and production parameter inversion of steam flooding.

In this paper, a numerical model of steam-flooding reservoir based on the finite volume method is established, and the Kriging method is used for stochastic geological modeling to provide random sample data considering reservoir heterogeneity for ANN training. By using the highly nonlinear global effect of ANN and its powerful self-adaptive and self-learning functions, the forward-looking and inverse design models of the steam-flooding reservoir based on ANN are established, which provides a new method for rapid prediction of production performance and fast design of production schedule parameters of steam-flooding reservoir.

\section{Reservoir Modeling and Data Preparation}

2.1. Basic Reservoir Numerical Model. Steam flooding is an effective way to develop heavy oil reservoir. It mainly uses steam injection wells to inject a large amount of hightemperature steam into heavy oil formation, so as to heat the heavy oil and reduce its viscosity, and to realize the purpose of displacing crude oil to producing well. At present, the main methods to predict the production performance of steam drive reservoir are the analytic method, empirical formula method, semianalytical method, and numerical simulation method. Among them, the numerical simulation method can more accurately judge the production performance of steam drive and the distribution characteristics of reservoir temperature and pressure and other parameters.

In solving mass and heat transfer of steam flooding, the calculation method based on temperature-pressure relationship of saturated steam needs to constantly judge the temperature-pressure relationship in the process of Newton iterations, which leads to low calculation efficiency. The conservation equations are constructed based on the components, the phase equilibrium constant is used to calculate the phase state, the relaxation variable is introduced, and the inequality constraint is added in the NR iteration, which can ensure the calculation efficiency.

\subsubsection{The Mass Conservation Equations of Components}

$$
\begin{aligned}
\frac{\partial\left(\rho_{w} \phi S_{w} y_{w}+\rho_{g} \phi S_{g} x_{w}\right)}{\partial t}+\frac{\partial\left(\rho_{w} u_{w} y_{w}+\rho_{g} u_{g} x_{w}\right)}{\partial x} & =\rho_{w} q_{w}, \\
\frac{\partial\left(\rho_{w} \phi S_{w} y_{N_{2}}+\rho_{g} \phi S_{g} x_{N_{2}}\right)}{\partial t}+\frac{\partial\left(\rho_{w} u_{w} y_{N_{2}}+\rho_{g} u_{g} x_{N_{2}}\right)}{\partial x} & =\rho_{g} q_{N_{2}}, \\
\frac{\partial\left(\rho_{o} \phi S_{o}\right)}{\partial t}+\frac{\partial\left(\rho_{o} u_{o}\right)}{\partial x} & =\rho_{o} q_{o} .
\end{aligned}
$$




\subsubsection{Energy Conservative Equation}

$$
\begin{aligned}
& \nabla\left(\lambda_{c} \nabla T\right)-\nabla\left(\rho_{w} h_{w} u_{w}\right)-\nabla\left(\rho_{o} h_{o} u_{o}\right)-\nabla\left(\rho_{s} h_{s} u_{s}\right) \\
& =\frac{\partial}{\partial t}\left[(1-\phi) \rho_{R} C_{R} T+\phi \rho_{o} S_{o} h_{o}+\phi \rho_{w} S_{w} h_{w}+\phi \rho_{s} S_{s} h_{s}\right] .
\end{aligned}
$$

\subsubsection{The Sum of Component Concentrations in a Phase Is 1}

Gas phase:

$$
\sum_{a} x_{a}=1
$$

Water phase:

$$
\sum_{a} y_{a}=1
$$

\subsubsection{Phase Equilibrium of Components}

Water component:

$$
x_{w}=K_{w}(p, T) y_{w} .
$$

Nitrogen component:

$$
y_{N_{2}}=0
$$

\subsubsection{Restriction Equation (Unequal Constraint)}

$$
y_{w}+v^{2}=1
$$

Based on the finite volume method satisfying the local conservation of mass, the partial differential equations are discretized, which can ensure local conservation of heat and mass transfer. Meanwhile, the parameters of the flow convection term and the thermal convection term are taken as the upstream weight scheme. Therefore, this paper uses adaptive-time-step Newton iteration and automatic differential method to solve the mathematical model. What needs to be pointed out is that reducing the initial time step and appropriately increasing the size of the grid are adopted to increase the convergence of the simulation.

\subsection{Input Parameters and Corresponding Data Preparation.} The sample data are the premise of the ANN model to accurately predict the production performance of steam drive reservoir. Permeability, porosity, and compressibility are the basic parameters of reservoir. How to deal with the heterogeneity of physical properties of steam flooding reservoir is an important problem. In the oilfield field, most of them can only effectively obtain the physical parameters around the well. Therefore, taking the two-dimensional model as an example, this paper randomly generates the permeability value of the grid where five wells are located and then obtains the permeability distribution of the whole reservoir model through Kriging interpolation, so as to reduce the number of input neurons in the neural network model in this paper and effectively describe the reservoir heterogeneity.

The Kriging interpolation method is often used in stochastic geological modeling. It is based on the basic principle that "similar geological locations have similar physical properties." Therefore, it is more suitable to use Kriging interpolation to generate reservoir permeability distribution randomly. Taking the two-dimensional model shown in Figure 1 as an example, the permeability values at five well points are randomly generated according to uniform distribution, and then, the interpolation weight coefficient in Kriging interpolation is calculated by using Gaussian variogram. Combined with the actual situation of the reservoir model in this paper, the block gold value of 20 , the range of $500 \mathrm{~m}$ and the arch height of 5000 are selected in the Gaussian variogram. Figure 1 shows the permeability distribution of a two-dimensional reservoir model generated by Kriging interpolation.

The BHP in the production stage is usually lower than the initial reservoir pressure, so the ratio of $\mathrm{BHP}$ to initial reservoir pressure (denoted as PBHP) [25] must be in the range of $0-1$. Therefore, in order to determine the range of random sampling, this paper takes $\mathrm{PBHP}$ as the input data of ANN model.

To sum up, the inputs of the forward neural network model in this paper include the following: (1) the permeability value at each well point; then, the permeability distribution of the whole reservoir is obtained by Kriging interpolation ( 5 neurons for the 2D model and 3 neurons for the $1 \mathrm{D}$ model); (2) well spacing, steam injection rate, and PBHP (totally three neurons).

\subsection{Output Parameters and Corresponding Data Preparation.} In this paper, a two-dimensional reservoir model with the size of $1400 \mathrm{~m} \times 1400 \mathrm{~m}$ is established. The thickness is $10 \mathrm{~m}$ and the number of grids is $10 \times 10$. The permeability distribution is generated randomly by the Kriging interpolation method, as shown in Figure 2. There is a steam injection well in the center of large and small reservoirs and a production well at each end of the reservoir. The initial formation pressure is $5 \mathrm{MPa}$, the steam injection rate is $152 \mathrm{t} / \mathrm{d}$, the initial reservoir temperature is $50^{\circ} \mathrm{C}$, the initial water saturation is 0.15 , the initial oil saturation is 0.85 , and the injection steam temperature is $350^{\circ} \mathrm{C}$. The production well is produced under constant bottom hole flow pressure.

The distribution of temperature, steam-phase, and water saturation calculated at 250 days are shown in Figure 3. It can be seen that, at 250 days, steam only exists in the grid where the steam injection well is located, and the water saturation is greatly increased compared with the initial value, which indicates that, under the initial temperature of the reservoir, all injected steam is condensed into hot water. Only when the grid temperature rises to meet the corresponding relationship of temperature and pressure for the existence of steam, there will be the steam phase. 


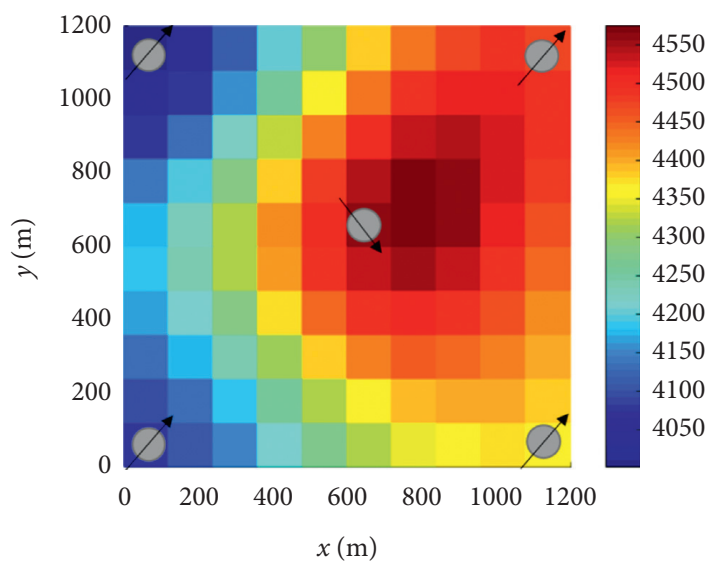

(a)

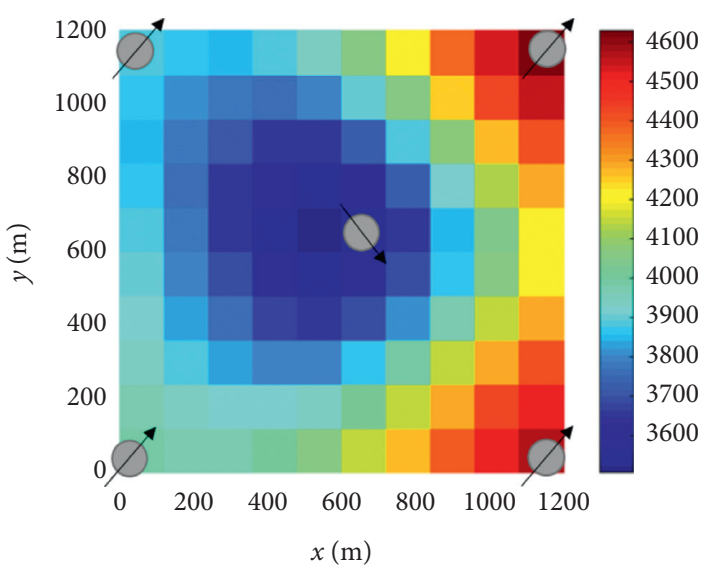

(b)

Figure 1: Permeability distribution of 2D reservoir model. (a) Case 1. (b) Case 2.

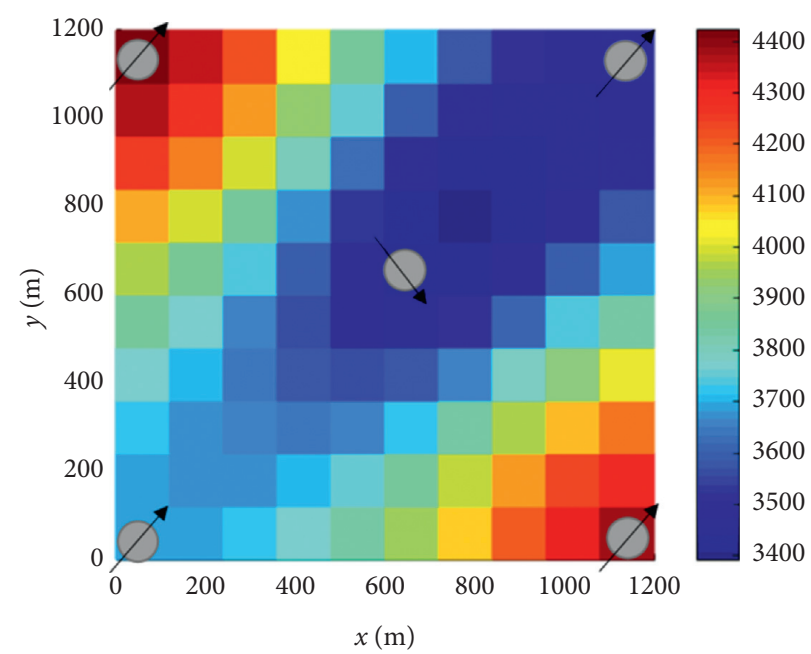

Figure 2: Two-dimensional steam drive reservoir model and its randomly generated permeability distribution.

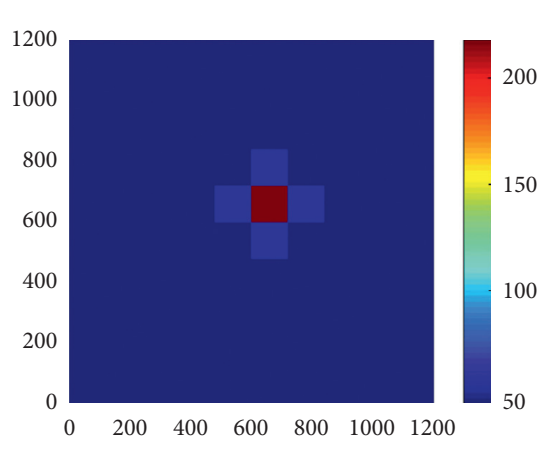

(a)

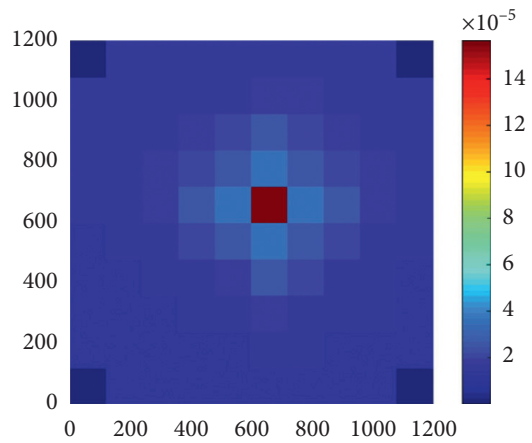

(b)

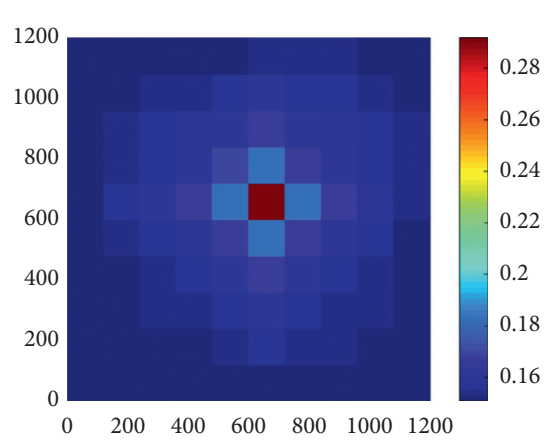

(c)

Figure 3: Distribution of temperature, steam content, and water saturation at 250 days. (a) Temperature field diagram. (b) Steam saturation field diagram. (c) Water saturation field diagram. 
For the oil field, the daily oil production or cumulative oil production of a well group or block is concerned. Therefore, a large number of reservoir models formed by random input data are simulated and calculated by using the established steam-drive numerical simulator, and the corresponding cumulative oil production curve is obtained, and 10 data points at the same time interval of the whole block cumulative oil production are taken as the output of the forward-looking ANN model.

\section{Establishment of Artificial Neural Network Model}

3.1. I/O Setup and ANN Topologies. In this paper, two kinds of neural network models are trained, i.e., the forward ANN model to predict the cumulative oil production of the block according to the reservoir permeability distribution, steam injection rate, and well spacing and the inversion ANN model which provides reasonable cumulative oil production to inverse the relevant parameters. Therefore, the input and output parameters of these two neural network models can be summarized as Table 1 .

Then, based on the range of random-sampling values of the parameters listed in Table 2, the numerical simulator generates 4250 samples randomly. Because Hornik [26] have proved that three-layer (i.e., one hidden layer) neural network can approximate any nonlinear continuous function, in order to simplify the complexity of training ANN architecture, this paper only considers the single hidden layer ANN architecture. The number of neurons in the hidden layer needs to be optimized. Therefore, the Levenberg-Marquardt (LM) algorithm is used to train the two single hidden layer neural networks, of which $70 \%$ are used for training, $15 \%$ for verification, and 15\% for testing. After repeated retraining to evaluate the robustness of the selected ANN architecture, the resulting ANN architecture is shown in Figure 4, in which there are 15 and 10 neurons in the hidden layer, respectively.

\section{Model Validation}

4.1. Validation of Forward-Looking ANN Model. Firstly, the relative error of cumulative oil production predicted by the forward ANN model can be calculated by the following equation:

$$
\text { relative error }=\frac{1}{10} \sum_{i=1}^{10}\left|\frac{q_{\mathrm{ANN}, i}-q_{\mathrm{FVM}, i}}{q_{\mathrm{FVM}, i}}\right|,
$$

where $q_{\mathrm{ANN}, i}$ and $q_{\mathrm{FVM}, i}$ denote the cumulative oil production calculated by the ANN model and numerical simulation, respectively.

In all 4250 test cases, the relative errors of predicted oil production are shown in Figure 5. It can be seen that the relative error of most cases is less than $0.1 \%$, and the relative error of all cases is generally less than $1 \%$. Therefore, the prediction results of the ANN model in this paper are well matched with the numerical simulation results. In order to display the comparison results more intuitively, based on the
TABLE 1: Input and output of the neural network model.

\begin{tabular}{lcc}
\hline Model components & $\begin{array}{c}\text { Forward- } \\
\text { looking }\end{array}$ & Inverse design \\
\hline Distribution of reservoir permeability & Input & Input \\
Steam injection rate & Input & Output \\
PBHP & Input & Output \\
Steam quality & Input & Output \\
Well distance & Input & Output \\
Cumulative oil production & Output & Input \\
\hline
\end{tabular}

TABle 2: Parameter summary and corresponding value range of random sampling.

\begin{tabular}{lccc}
\hline Parameter & Unit & Minimum & Maximum \\
\hline Permeability & $\mathrm{mD}$ & 1200 & 6000 \\
Injection rate & $\mathrm{m}^{3} \cdot \mathrm{d}$ & 5000 & 6000 \\
Well distance & $\mathrm{m}$ & 300 & 400 \\
Steam quality & Fraction & 0.3 & 1 \\
PBHP & Fraction & 0.3 & 0.6 \\
\hline
\end{tabular}

relative error, the prediction results of the forward ANN model are divided into two categories (i.e., excellent and good) in Figure 6, showing some comparisons of cumulative oil production.

4.2. Validation of Inverse Project Design ANN Model. The relative errors of cumulative oil production in all 4250 cases is plotted in Figure 7, and some comparison results of the ANN model are listed in Table 3. We can see that these results have a good match. In 4250 samples, the error of cumulative oil production is usually less than $15 \%$. This shows that the developed inversion ANN model can give a reasonable steam-drive development plan, which meets the input reservoir parameters and expected plan. In addition, we can see that the relative error of the inverse ANN model is significantly larger than that of the forward model, which may be caused by multiple solutions of the inversion problem.

\section{Applications of Developed ANN Models}

5.1. Efficient Parametric Studies of Steam Drive Project. As discussed in the third lecture, the forward ANN model can quickly and accurately estimate the production performance of steam flooding. This paper will analyze the influence of steam injection rate, well spacing, permeability distribution, and steam dryness on cumulative oil production in the block, as a simple application of the ANN model.

This section uses the data in Table 4 as the basic input data and adopts different values of one parameter to compare the corresponding cumulative oil production to make the parametric study of well space, PBHP, steam injection rate, and steam quality.

It can be seen from Figure 8(a) that, in the early stage of reservoir production, the reservoir model with smaller well spacing produces more oil, but in the later stage of production, the production of the model with smaller well spacing will be lower than that of the model with larger well 


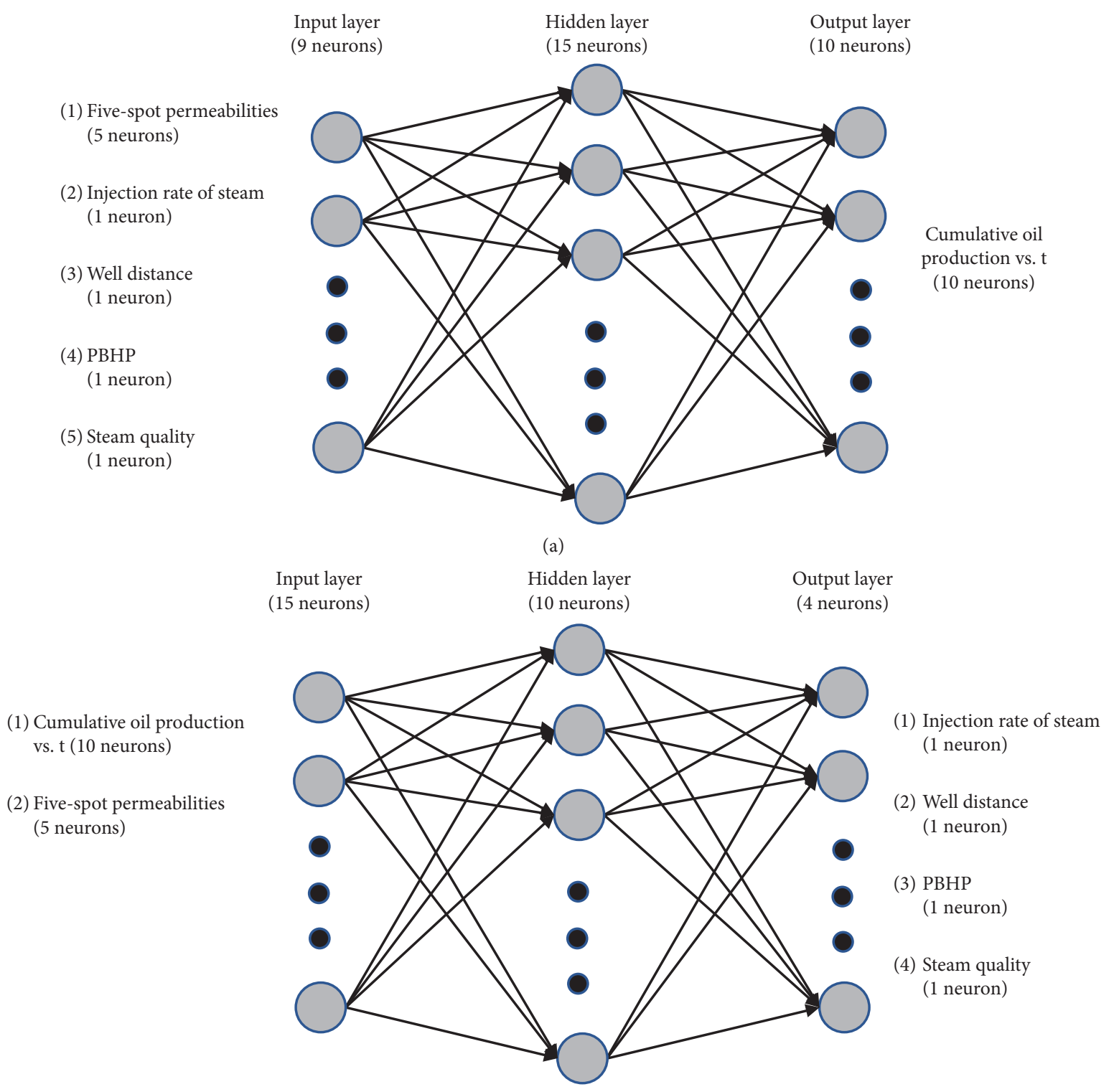

(b)

FIgURE 4: The topological structure of the neural network model in this paper. (a) The look-forward model. (b) The inverse design model.

spacing due to insufficient formation energy. From Figure 8(b), we can see when the bottom hole pressure is smaller, the production pressure difference is larger, and the oil production will be more; as can be seen from Figure $8(\mathrm{c})$, when the steam injection speed is higher, the oil production will be increased. The better the effect of steam flooding is, the more oil is produced; as can be seen from Figure 8(d), the oil production is driven by the production pressure difference in the initial stage of production, so the influence of dryness on the oil production in the early stage of production is small, but in the middle and late stage of production, the injected steam begins to take effect. At this time, the greater the steam quality and the more heat the injected steam contains, the more oil will be produced. It can be seen that the parametric study by the forward looking ANN model reflects the actual effect of various parameters to steam flooding reservoir, but the parameter study based on the ANN model is much faster than that based on traditional numerical simulation, which proves the practical significance of the ANN model in this paper.

5.2. Uncertainty Analysis of the Engineering Design Parameters. The uncertainty of the inverse project design ANN model is analyzed by the Monte Carlo simulation method. The probability density distribution of four key steam drive engineering parameters is explored on the premise that the input parameters obey normal distribution 


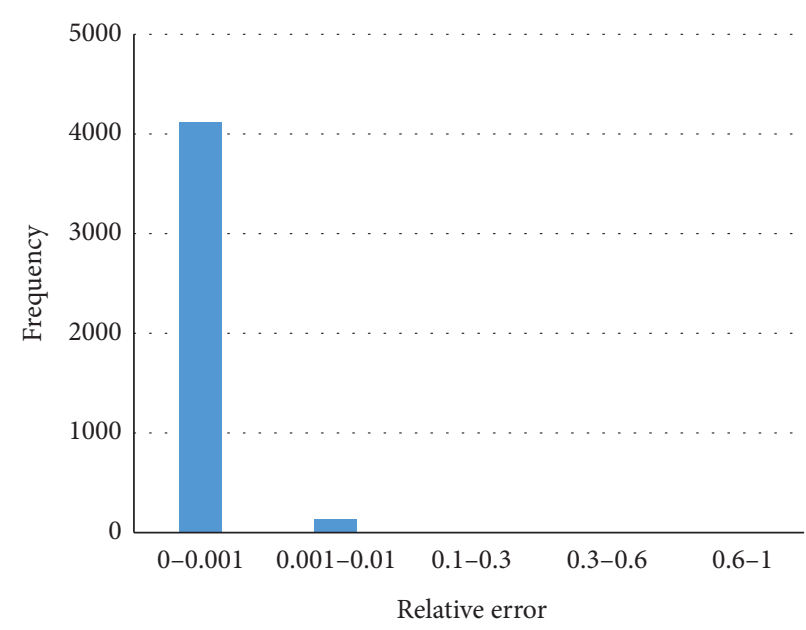

(a)

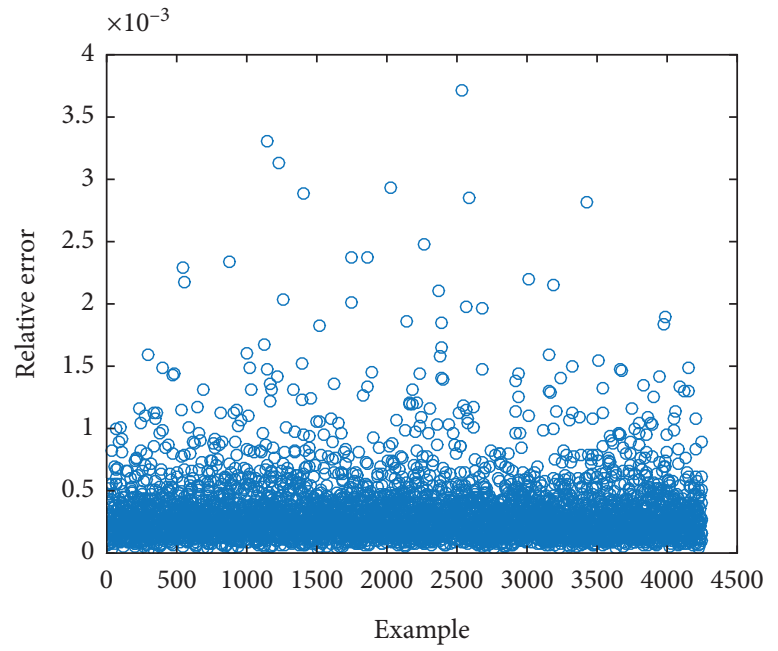

(b)

FIGURE 5: Relative error of the forward ANN model. (a) Relative error bar chart. (b) Relative error scatter chart.
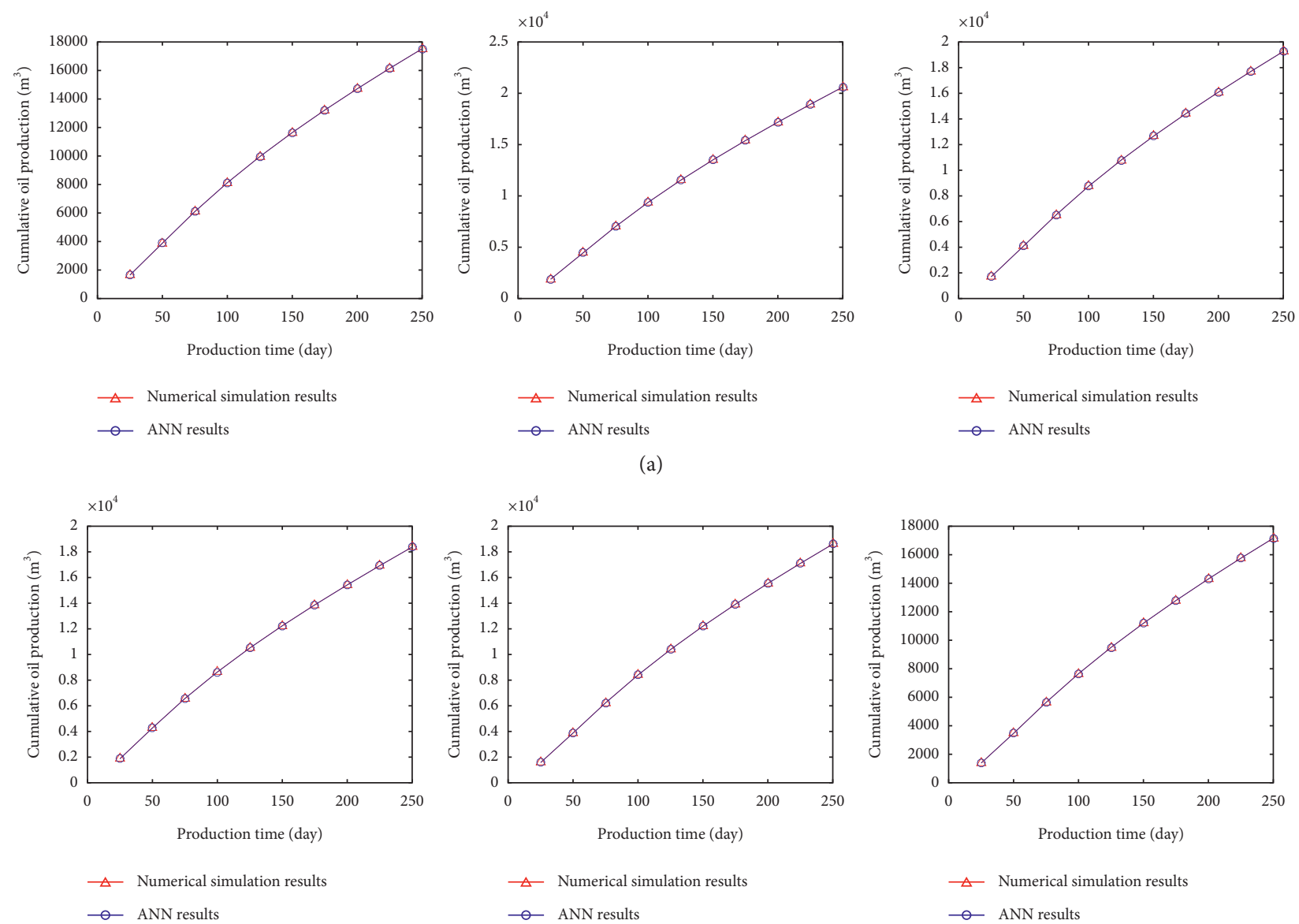

(b)

FIgURE 6: Comparison of cumulative oil production between numerical simulation and forward ANN model. (a) Excellent. (b) Good.

[27]. The expectations and standard deviation of normal distribution of all input parameters are shown in Table. 5. The probability density functions of well spacing, steam injection rate, $\mathrm{PBHP}$, and steam quality are shown in Figure 9. These probability density functions are obtained through 200,000 Monte Carlo simulations. 


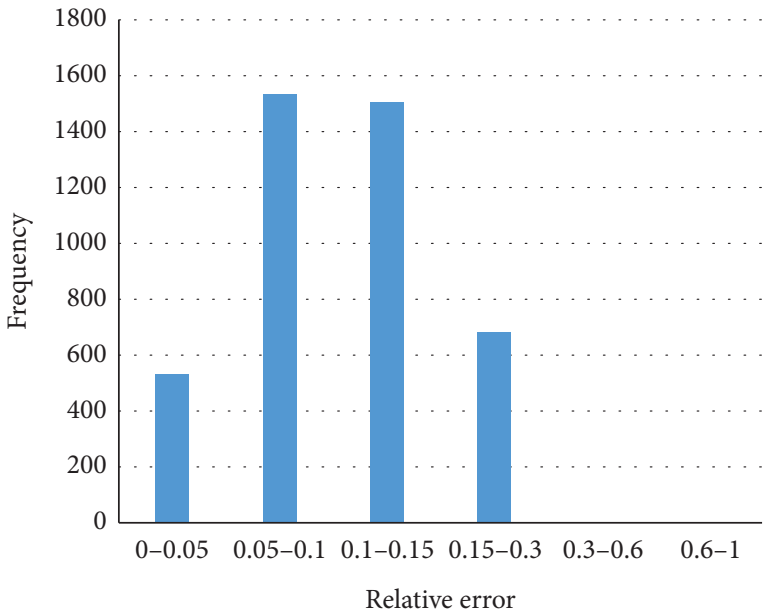

(a)

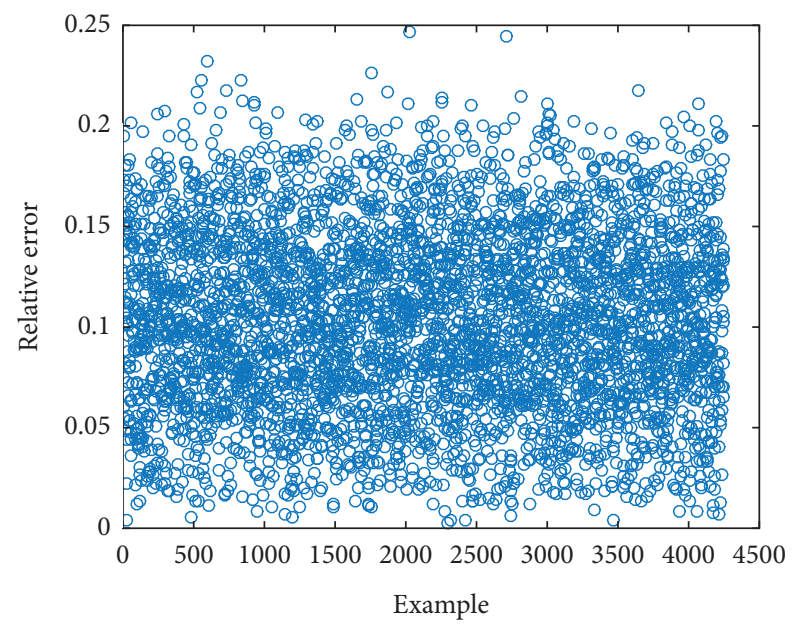

(b)

FIGURE 7: Distribution of relative error of ANN model inversion. (a) Bar chart of relative error distribution. (b) Scatter chart of relative error.

TABLE 3: Analysis of partial results of ANN inversion model.

\begin{tabular}{|c|c|c|c|c|c|c|c|c|c|}
\hline \multirow[t]{2}{*}{ Type } & \multicolumn{2}{|c|}{ PBHP (fraction) } & \multicolumn{2}{|c|}{$\begin{array}{l}\text { Steam quality } \\
\text { (fraction) }\end{array}$} & \multicolumn{2}{|c|}{ Well spacing (m) } & \multicolumn{2}{|c|}{$\begin{array}{l}\text { Steam injection } \\
\text { rate }\left(\mathrm{m}^{3} \cdot \mathrm{d}\right)\end{array}$} & \multirow[t]{2}{*}{ Relative error (\%) } \\
\hline & Real & ANN & Real & ANN & Real & ANN & Real & ANN & \\
\hline \multirow{2}{*}{ Good } & 0.4810 & 0.4761 & 0.6683 & 0.6697 & 304.84 & 305.58 & 5667.9 & 5667.1 & 0.38 \\
\hline & 0.4471 & 0.4487 & 0.6066 & 0.5957 & 360.44 & 360.64 & 5944.9 & 5944.9 & 0.55 \\
\hline \multirow{2}{*}{ Qualified } & 0.4439 & 0.4460 & 0.8609 & 0.6655 & 398.99 & 398.92 & 5527.8 & 5527.9 & 7.47 \\
\hline & 0.5216 & 0.4564 & 0.7102 & 0.6597 & 357.46 & 357.59 & 5845.2 & 5845.6 & 5.5 \\
\hline \multirow{2}{*}{ Bad } & 0.5637 & 0.4616 & 0.9922 & 0.6374 & 358.28 & 357.28 & 5815.4 & 5814.7 & 19.52 \\
\hline & 0.5189 & 0.4500 & 0.9235 & 0.5998 & 362.59 & 362.82 & 5660.9 & 5661.0 & 17.34 \\
\hline
\end{tabular}

TABLE 4: Basic input parameters of the forward-looking ANN model.

\begin{tabular}{lcc}
\hline Parameter & Unit & Expectation \\
\hline Five-spot permeability & $\mathrm{D}$ & 4 \\
Well space & $\mathrm{m}$ & 350 \\
Steam injection rate & $\mathrm{m}^{3} / \mathrm{d}$ & 5500 \\
PBHP & Fraction & 0.5 \\
Steam quality & Fraction & 0.7 \\
\hline
\end{tabular}




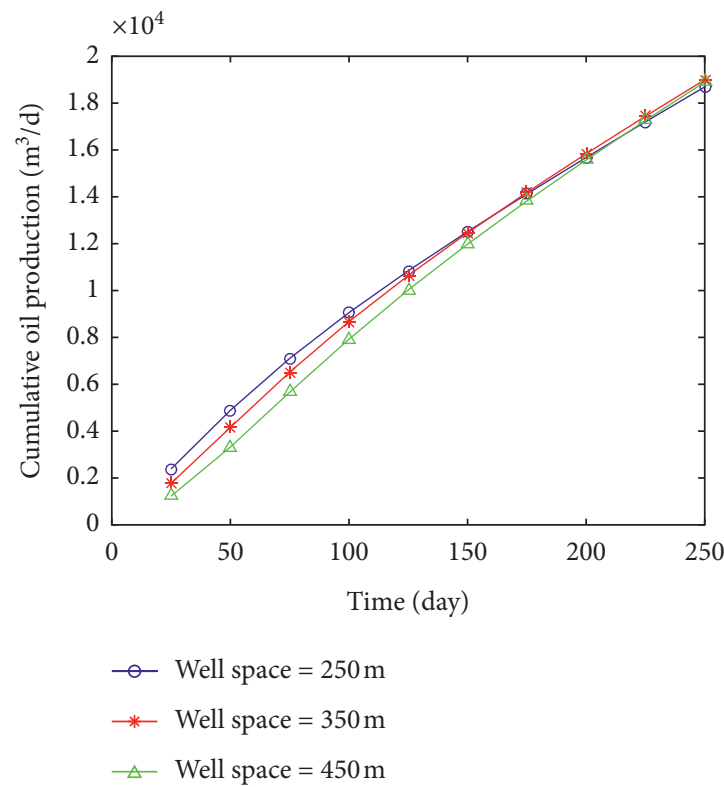

(a)

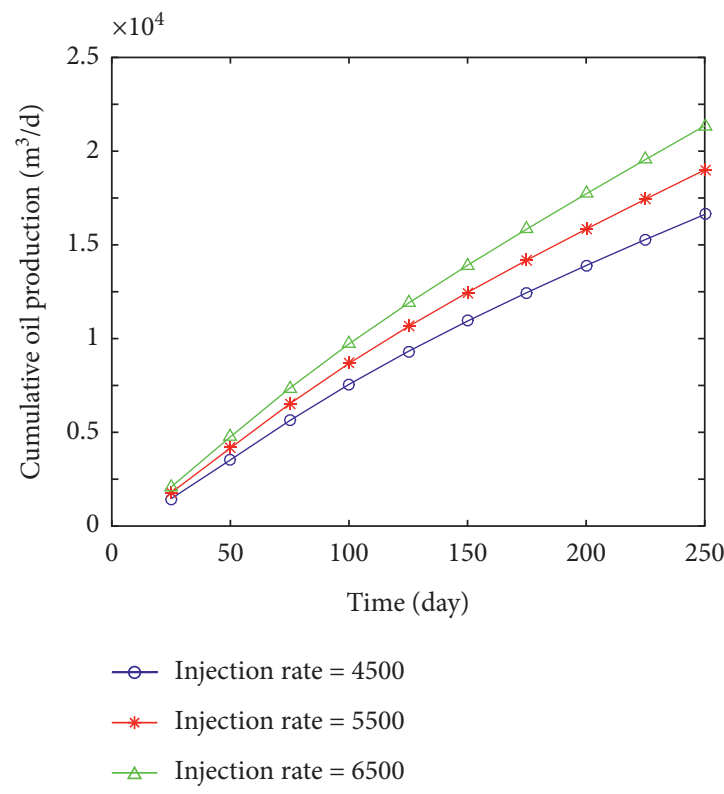

(c)

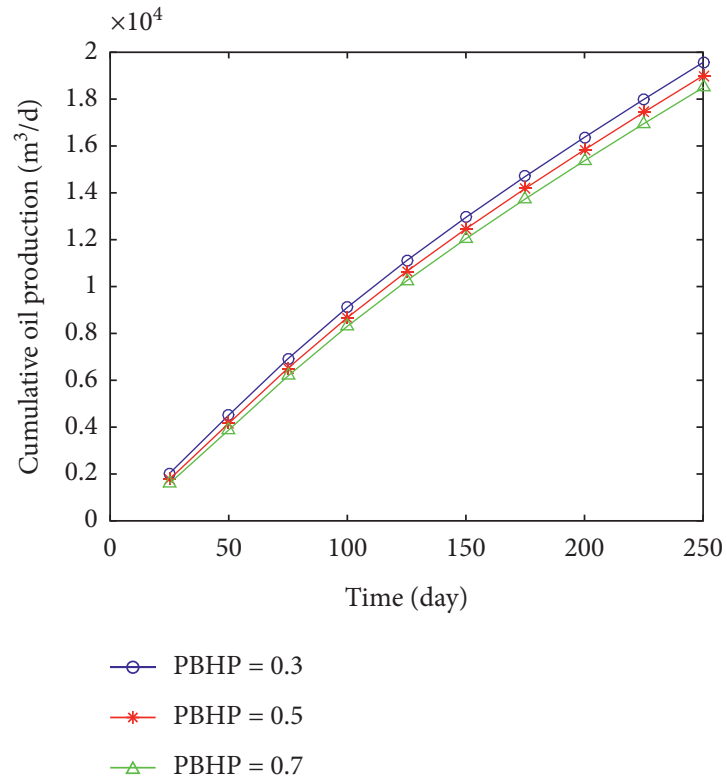

(b)

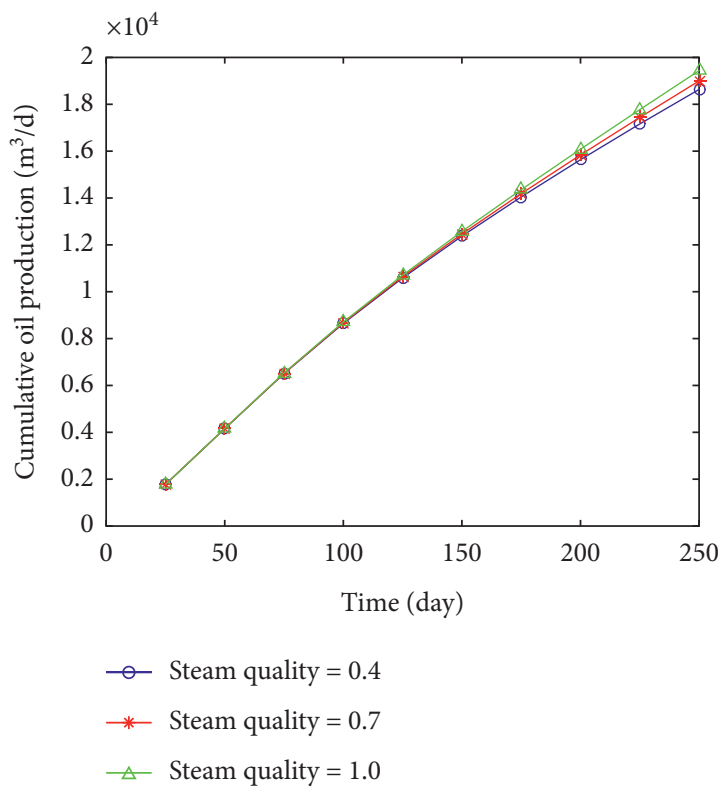

(d)

FIGURE 8: Sensitivity of cumulative oil production to project parameters. (a) Well space. (b) PBHP. (c) Injection rate. (d) Steam quality.

TABLE 5: Summary of the parameters for normal distributions of all input parameters in the inverse project design ANN model.

\begin{tabular}{lcccc}
\hline Category & Parameter & Unit & Expectation & Standard deviation \\
\hline & Permeability of injector & D & 3.46 & 0.1 \\
Five-spot permeability & Permeability of producer 1 & D & 4.37 & 0.1 \\
& Permeability of producer 2 & D & 4.41 & 0.1 \\
& Permeability of producer 3 & D & 4.38 & 0.1 \\
& Permeability of producer 4 & D & 4.42 & 0.1 \\
\hline
\end{tabular}


TABle 5: Continued.

\begin{tabular}{|c|c|c|c|c|}
\hline Category & Parameter & Unit & Expectation & Standard deviation \\
\hline \multirow{10}{*}{ Data of cumulative oil production } & Change rate of $909 \mathrm{~m}^{3}$ & Fraction & 0 & 0.01 \\
\hline & Change rate of $2101 \mathrm{~m}^{3}$ & Fraction & 0 & 0.01 \\
\hline & Change rate of $3261 \mathrm{~m}^{3}$ & Fraction & 0 & 0.01 \\
\hline & Change rate of $4315 \mathrm{~m}^{3}$ & Fraction & 0 & 0.01 \\
\hline & Change rate of $5274 \mathrm{~m}^{3}$ & Fraction & 0 & 0.01 \\
\hline & Change rate of $6163 \mathrm{~m}^{3}$ & Fraction & 0 & 0.01 \\
\hline & Change rate of $7004 \mathrm{~m}^{3}$ & Fraction & 0 & 0.01 \\
\hline & Change rate of $7811 \mathrm{~m}^{3}$ & Fraction & 0 & 0.01 \\
\hline & Change rate of $8593 \mathrm{~m}^{3}$ & Fraction & 0 & 0.01 \\
\hline & Change rate of $9357 \mathrm{~m}^{3}$ & Fraction & 0 & 0.01 \\
\hline
\end{tabular}

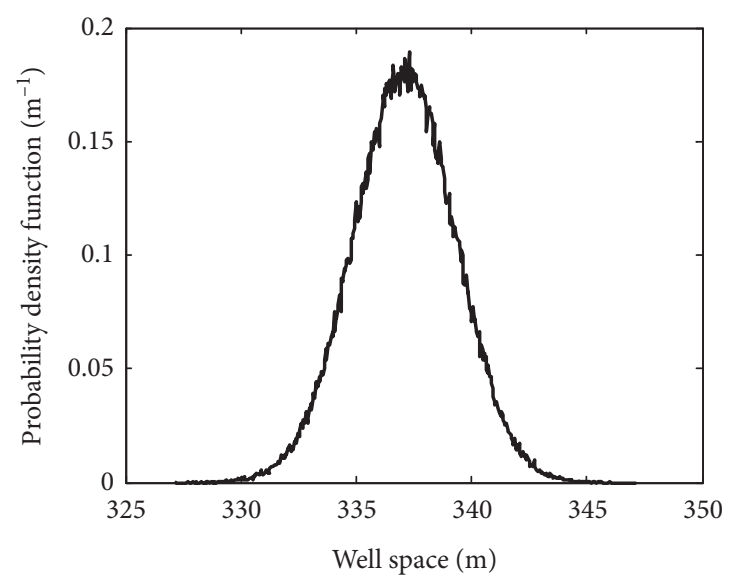

(a)

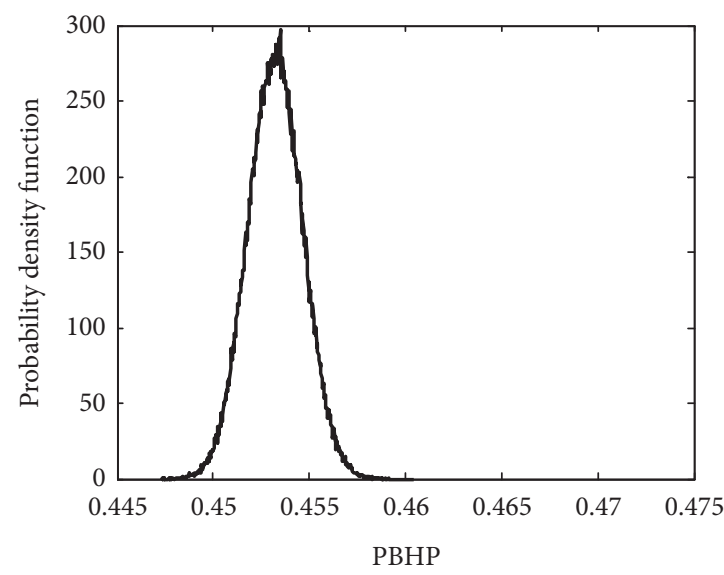

(c)

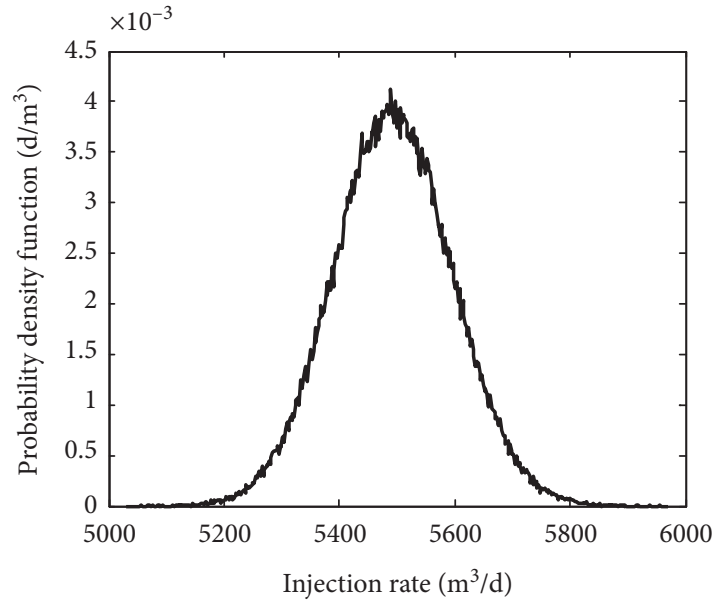

(b)

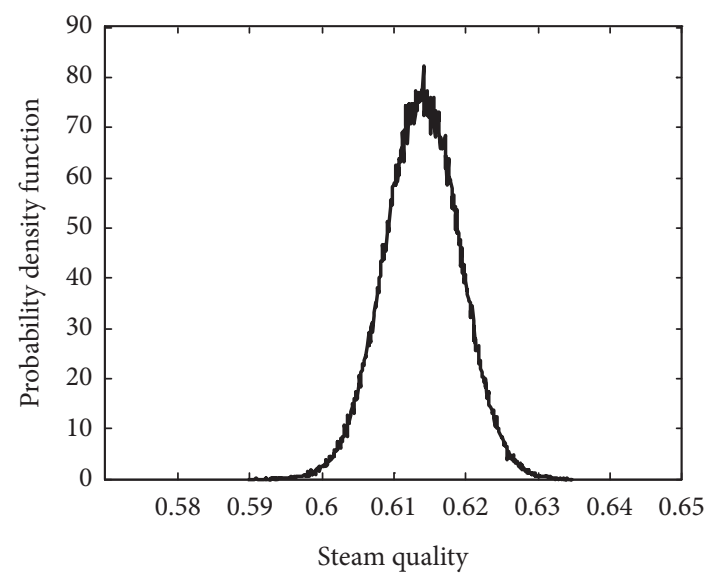

(d)

FIGURE 9: The probability density functions of four engineering parameters. (a) Well space. (b) Injection rate. (c) PBHP. (d) Steam quality.

\section{Conclusion}

Throughout the whole paper, several key conclusions are obtained:

(1) A numerical simulation technology of steam flooding reservoir based on the finite volume method is firstly established. Combined with the component model, the fully implicit solution for steam flooding is carried out by using the adaptive-time-step Newton iteration method.

(2) The Kriging method is used to stochastically generate 4250 geological model samples by considering reservoir heterogeneity, and corresponding production schedule parameters are randomly given; then, these reservoir model samples are handled by the numerical simulation technology to obtain 
corresponding dynamic production data, which constitute the data for artificial neural network (ANN) training.

(3) In this paper, the forward-looking ANN model can quickly and accurately predict the production performance of steam flooding reservoir by inputting reservoir physical parameters and production parameters. The inverse design ANN model can be used to efficiently retrieve the production parameters of steam flooding reservoir according to the cumulative oil production data of the reservoir.

(4) In training results of 4250 groups of sample data, the error of forward-looking model is less than $0.1 \%$, and the error of inverse design model is generally less than $15 \%$. The effectiveness of the developed ANN models is fully illustrated with this paper.

(5) Parametric studies are implemented by the forwardlooking ANN model to analyze the influencing factors of steam-flooding process, and uncertainty analysis of the inverse design ANN model is conducted to validate its robustness.

\section{Data Availability}

The data used to support the findings of this study are available from the corresponding author upon request.

\section{Conflicts of Interest}

The authors declare that they have no conflicts of interest.

\section{Acknowledgments}

This study was supported by Cooperative Innovation Center of Unconventional Oil and Gas (Ministry of Education \& Hubei Province), Yangtze University (no. UOG2020-17) and the National Natural Science Foundation of China (nos. 51874044 and 51922007).

\section{References}

[1] H. Chen, Y. Liu, J. Bai, Z. Jiang, M. Pang, and H. Li, "Study on injection production integrated technology of heavy oil thermal recovery well in offshore oilfield," Petroleum Machinery, vol. 48, no. 4, p. 43, 2020.

[2] W. Xie, X. Li, Z. Chen et al., "Overview of exploration and development technology for heavy oil and high pour point oil in Liaohe oil region," Acta Petrologica Sinica, no. 4, p. 145, 2007.

[3] Y. Zhang, G. Yu, J. Zhu, C. Liang, and F. Cai, “Optimization design of injection and production parameters for heavy oil steam flooding: a case study of heavy oil block in block 3 of Jinglou oilfield, Henan oilfield," Acta Petroleum and Natural Gas, vol. 31, no. 2, p. 336, 2009.

[4] H. Yulan, Z. Wang, D. Yuan et al., "Research progress of steam injection oil recovery in China," Chemical Bulletin, vol. 77 , no. 2 , p. 137, 2014.

[5] C. Feng, C. Wang, R. Zhang et al., "Gravity water-drainage assisted steam flooding of heavy oil: 3D physical modeling experiment," Xinjiang Petroleum Geology, vol. 40, no. 4, p. 464, 2019.
[6] B. Guo, R. Lin, Z. Wang, Q. Ma et al., "Experiment and mechanism analysis of superheated steam to improve oil displacement effect," Xinjiang Petroleum Geology, vol. 40, no. 4 , p. 481, 2019.

[7] G. Wei, G. Hu, and M. Yan, "Steam flooding mechanism," Special Oil and Gas Reservoirs, no. S1, p. 7, 1996.

[8] V. Ma, B. B. Maini, and T. Okazawa, "Laboratory simulation of steam drive process," in Proceedings of the 1984 Annual Technical Meeting, Calgary, Canada, 1984.

[9] F. S. Johnson, C. J. Walker, and A. F. Bayazeed, "Oil vaporization during steamflooding," Journal of Petroleum Technology, vol. 23, no. 6, pp. 731-742, 1968.

[10] C. W. Shen, "Application of a scaled, three-dimensional highpressure physical model to steamflooding," in Proceedings of the 17th Annual Convention of the Indonesian Petroleum Association, pp. 109-128, Indonesian Petroleum Association, Jakarta, Indonesia, 1988.

[11] J. W. Marx and R. H. Langenheim, "Reservoir heating by hot fluid injection," Transactions of the AIME, vol. 216, pp. 312365, 1959.

[12] J. Van Lookeren, "Calculation methods for linear and radial steam flow in oil reservoirs," Society of Petroleum Engineers Journal, vol. 23, no. 3, 1977.

[13] Y. Chen, Steam Injection Thermal Oil Recovery, Petroleum University Press, Dongying, China, 1996.

[14] S. J. Torabzadeh and M. Kumar, "Performance correlation for steamflood field projects," in Proceedings of the SPE California Regional Meeting, Ventura, CA, USA, April 1990.

[15] X. J. Gao, X. Yu, and S. Li, "Using neural network technology to predict remaining oil distribution," Acta Petrolei Sinica, vol. 26, no. 3, p. 60, 2005.

[16] A. Wang, Y. Zhang, and J. Gao, "Application of artificial neural network method to determine rock compressibility," Petroleum Exploration and Development, vol. 30, no. 4, pp. 105-107, 2003.

[17] H. Ni, W. Wang, and S. Luo, "Application of artificial neural network in oil production forecasting," Journal of Shaanxi Institute of Technology (Natural Science Edition), vol. 24, no. 3, p. 37, 2008

[18] Q. Sun and T. Ertekin, "Structuring an artificial intelligence based decision making tool for cyclic steam stimulation processes," Journal of Petroleum Science and Engineering, vol. 154, pp. 564-575, 2017.

[19] X. Rao, H. Zhao, and Q. Deng, “Artificial-neural-network (ANN) based proxy model for performances forecast and inverse project design of water huff-n-puff technology," Journal of Petroleum Science and Engineering, vol. 195, Article ID 107851, 2020.

[20] L. Qu, X. Li, C. Du et al., "Prediction model of carbon steel regional soil corrosion based on BP artificial neural network method," Journal of Beijing University of Science and Technology, vol. 31, no. 12, p. 1569, 2009.

[21] J. Zhou, B. W. Gui, M. Li, and L. Wen, "Application of artificial neural network based on rock control in permeability prediction," Acta Petroleum Sinica, vol. 31, no. 6, p. 985, 2010.

[22] J. Cai, Y. Zeng, H. Zhou et al., "High frequency radar wind speed retrieval based on artificial neural network," Acta Oceanographica Sinica, vol. 41, no. 11, p. 150, 2019.

[23] L. Yuan, X. Yang, and B. Wang, "Time reversal channel prediction based on neural network model optimized by genetic algorithm based on empirical knowledge," Acta Physica Sinica, vol. 68, no. 17, p. 72, 2019.

[24] X. Lei, J. Liu, S. Luo, and J. Cai, "Back analysis of tunnel surrounding rock parameters in water diversion system based 
on BP artificial neural network," Hydropower and Energy Science, vol. 31, no. 7, p. 115, 2013.

[25] Z. Song, B. Li, and X. Wang, "Inversion of soil permeability parameters of high slope in middle route project based on neural network," Journal of Yangtze River Academy of Sciences, vol. 26, no. S1, p. 29, 2009.

[26] K. Hornik, "Approximation capabilities of multilayer feedforward networks," Neural Networks, vol. 4, no. 2, pp. 251-257, 1991.

[27] H. Liu, X. Rao, and H. Xiong, "Evaluation of $\mathrm{CO}_{2}$ sequestration capacity in complex-boundary-shape shale gas reservoirs using projection-based embedded discrete fracture model (pEDFM)," Fuel, vol. 277, Article ID 118201, 2020. 